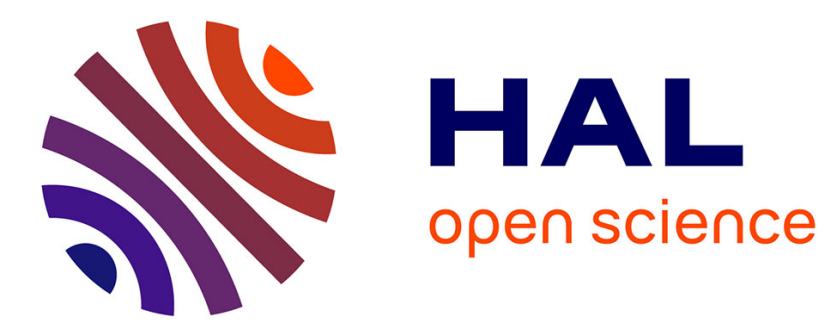

\title{
Synthetic Situations in the Internet of Things
}

Elena Parmiggiani, Eric Monteiro, Thomas Østerlie

\section{To cite this version:}

Elena Parmiggiani, Eric Monteiro, Thomas Østerlie. Synthetic Situations in the Internet of Things. Working Conference on Information Systems and Organizations (ISO), Dec 2016, Dublin, Ireland. pp.215-228, 10.1007/978-3-319-49733-4_13 . hal-01619203

\section{HAL Id: hal-01619203 \\ https://hal.inria.fr/hal-01619203}

Submitted on 19 Oct 2017

HAL is a multi-disciplinary open access archive for the deposit and dissemination of scientific research documents, whether they are published or not. The documents may come from teaching and research institutions in France or abroad, or from public or private research centers.
L'archive ouverte pluridisciplinaire HAL, est destinée au dépôt et à la diffusion de documents scientifiques de niveau recherche, publiés ou non, émanant des établissements d'enseignement et de recherche français ou étrangers, des laboratoires publics ou privés. 


\title{
Synthetic Situations in the Internet of Things
}

\author{
Elena Parmiggiani ${ }^{1}$, Eric Monteiro ${ }^{1}$, and Thomas $\varnothing_{\text {sterlie }}{ }^{1,2}$ \\ ${ }^{1}$ NTNU, Department of Computer and Information Science, Trondheim, Norway \\ \{parmiggi, eric.monteiro\}@idi.ntnu.no \\ ${ }^{2}$ NTNU Social Research, Trondheim, Norway \\ thomas.osterliedsamfunn.ntnu.no
}

\begin{abstract}
The proliferation of distributed digital technologies in contemporary enterprise challenges the understanding of situated action. This paper revisits this notion in the era of Big Data and the Internet of Things. Drawing upon longitudinal studies within the offshore oil and gas industry, we empirically expand upon Knorr Cetina's "synthetic situation" to encompass data-intensive work where people are not co-located with the physical objects and phenomena around which work is organized. By highlighting the performative nature of synthetic situations in the Internet of Things - where phenomena are algorithmically enacted through digital technologies - we elaborate upon the original formulation of synthetic situations by demonstrating that (i) algorithmic phenomena constitute the phenomena under inquiry, rather than standing in for physical referents; (ii) noise is irreducible in algorithmic phenomena; (iii) synthetic situations are productive rather than reductive. Finally, we draw brief methodological implications by proposing to focus on the material enactment of data in practice.
\end{abstract}

Keywords: Synthetic situation $\cdot$ performativity $\cdot$ algorithmic phenomena $\cdot$ Internet of Things.

\section{$1 \quad$ Introduction}

Few notions in social informatics have been as cherished and influential as that of "situated action" [1]. The notion of situated action underscores the inherent contingencies of how work practices, very much including use of technology, unfold. The notion has been crucial in debunking deterministic influences [2]. That action is situated is accordingly firmly established. What remains unclear, however, is where, how, and when the situation influences action. What, exactly, is a "situation"?

This question is increasingly pressing as modern work practices are growing more information-saturated and dependent on interconnected and interacting heterogeneous information and communication technologies (ICTs) - such as networks of remote sensors, gadgets, and artefacts - going under the banner of the Internet of Things (IoT), generating vast amounts of quantified datasets (Big Data) [3]. The increased prominence of mediated information (sensor data, images, visualizations, algorithm calculations) transforms the conditions for work [4], particularly in data-saturated settings such as the oil and gas industry [5]. Focusing on how situated actions are shaped through 
distributed, interacting, and remote technologies, implies a shift of analytical focus towards performativity, namely on the way assemblages of tools, concepts, and expectations that we use in order to act on and conceive of objects also shape a situation [6].

The purpose of this paper is therefore to discuss the qualifier "situated" in "situated action". More specifically, we analyse and discuss the performativity of the material aspects of the "situation" in modern, technology-saturated settings. We engage with a stream of research which has debated the under-specification of what goes into the "situation" $[7,8]$, notably critiquing the understanding of "situation" as overly physical, i.e. too closely tied to the local, physical site $[9,10]$. In particular, we build upon Knorr Cetina's notion of synthetic situation, originally developed to theorize situations where people find themselves in one another's presence without needing to be physically colocated [7]. We extend upon her work to also encompass situations where people are not co-located with the physical phenomena their work is organized around, i.e. synthetic situations in the Internet of Things.

We draw upon empirical insights from two studies within the offshore oil and gas industry, a reality where work is conducted by necessity in the midst of a "datafication" [4]. That is, how situated action is laid out and constituted through the material aspects of (sometimes faulty) sensors, data streams, measurement devices, and heterogeneous on-screen representations.

We contribute towards current debates on conceptualizing digital technologies in contemporary work and organizing [11]. While the majority of the notions of situation in the literature are shaped by empirical settings that vary in terms of distribution, our notion of situation also varies in terms of material configuration. A performative rather than representational approach is a defining feature of the programme on materiality in Information Systems (IS) aiming to understand the ways in which people and technologies, their properties and boundaries, are enacted and reenacted in practice [12]. Our contribution therefore offers a way of exploring how material reality is performed in action through the arrangements for knowing about these phenomena, and how these arrangements are made to endure across space and time $[11,12]$.

\section{Theory}

\section{$2.1 \quad$ (Re-)conceptualizing Situated Action}

The fundamental, compelling insight of situated action is that action is not determined by design or constraints. Action is contingent, based on local circumstances and resources. As Suchman [13] expresses in revision to her 1987 book:

[A]ll activity, even the most analytic, is fundamentally concrete and embodied [...] however planned, purposeful actions are inevitably situated actions. By situated actions I mean simply actions taken in the context of the particular, concrete circumstances. (pp. 25-26)

Thus there is a radical indeterminacy of action that effectively undermines overly structural accounts. Viewed in this way, action is situated. Where unclarity, disagreement, and debate start, is when it comes to detailing our understanding of the meaning of 
Suchman's "context of the particular, concrete circumstance" [13] (p. 26). Several criticisms have been levelled at this idea, in the recent literature.

An important strand of critique is that Suchman's "particular, concrete circumstance" suggests an overly physical, space-time bounded meaning of the situation. ${ }^{1}$ When for instance Orlikowski [2] points out that "every encounter with technology is temporally and contextually provisional, and thus there is, in every use, always the possibility of a different structure being enacted" (p. 412), Kallinikos [9] argues that this forefronts the "here and now" of the users' encounters in front of a computer screen. A space-and-time conflated understanding of "situation" marginalizes to the level of nonexistence historical and institutional precursors as:

the activities that take place at the human-technology interface cover but a limited area of a wider system of instrumental relations, sustained by a huge network of technical, organization, and social arrangements that render the functionality and contextual enactment of a specific technology possible. [9] (p. 237)

Similarly, but with attention to potential biases associated with ethnographic methods, Williams and Pollock [10] identify a "localist sentiment", i.e. a tendency to conceptualize the "situation" as the physical and local site of investigation. In an effort to go beyond "localist" understandings of "situation" that do not fit modern work and organizing, Pollock et al. [8] propose the notion of an "extended situation", where

aspects once seen as central to localist analysis (co-location, proximity, etc.) are no longer the primary organizing features of [distributed work] as others begin to emerge, but also to show how the "where" of this form of work is now mediated by technology. [8] (p. 255)

Monteiro and Rolland [14] address how dependencies and similarities between distributed work practices emerge. The discretion of situated action is not unbounded - as Orlikowski [2] makes clear, "[s]aying that use is situated and not confined to predefined options does not mean that it is totally open to any and all possibilities" (p. 409). Acknowledging this, Monteiro and Rolland [14] point out that this leaves unaccounted the emergence of standardized (in the sense of similar but not identical) work practices, which they coin "trans-situated".

Thus, the empirical and theoretical understanding of the "situated" needs to be problematized in light of the increasing technology mediation in modern work. Knorr Cetina [7] showcases that the work practices of financial traders are situated with reference to both the individual trading floors and, simultaneously, the technology that facilitates interaction between the different trading floors. She proposes the notion of a "synthetic situation" to conceptualize how a "situation" emerges and is constituted by computerbased projections. In studying the shift in the organization of financial trading from physically co-located to distributed and electronically mediated, she defines synthetic situations as translocal "environments that are augmented and temporalized by (fully

1 This is not a critique of the concept itself - "situated" clearly was intended to be empirically open by Suchman, in line with her ethnomethodological affinities - but rather to the studies, often ethnographically inspired, that build on the notion. 
or partially) scoped components" [7] (p. 69). The concept of synthetic situation therefore underlines how representations on the screen (numbers, graphs, charts) are constitutive elements of the situation of the traders, functioning like a "scoping system", i.e. "an arrangement of hardware, software, and human feeds that together function like a scope" to observe, project, and augment a given reality [7] (p. 64). They are as "real" as physical and social circumstances, but enable traders to reach beyond the physical setting and, in so doing, constitute a reality by stitching together all the aspects that might be relevant to the interaction [7]. The discourse on sociomateriality has recently expanded Knorr Cetina's work by further conceptualizing how the materiality underlying technical and social connections enacts synthetic situations in practice - and therefore aspects of relevance, accountability, and division of labour [11].

In summary, a prominent aspect of the under-specification of the "situation" is the importance of technological mediation (distribution, representations). The role of technological mediation enacted by scoping systems needs to be recast as the intertwining (alternatively: entanglement, mutually constitutive, reciprocal relationship) of the social and the technical (or, more broadly, the material). Despite repeated calls to eliminate the dichotomy between the social and the material [11], however, "the social almost always seems to take precedence, the material merely affording some social/human intention" [12] (p. 816). The slogan "matter matters" [6] is sometimes exactly that, a slogan. As a result, the detailing of how - not only that - materiality matters (viz. its performativity) in modern work settings requires further analysis.

\subsection{Situating Action in the Internet of Things}

Information-saturated "synthetic situations" are not merely representations of sensorbased and otherwise mediated information; they are re-presented. There is an active appropriation and sense-making that goes beyond the passive imaginary of ICT "mediated" information. In contrast with the understanding of ICT mediation that downplays to the level of non-existence the transformative aspects involved in re-presenting, a focus on materiality as performative recognizes that modern "organizations are increasingly depending on such open-ended phenomena as large-scale data capture and dynamic algorithmic evaluation of online activity" [15] (p. 7).

Accordingly, this paper is concerned with situations where encoded, digital objects by necessity play a central role because of the distribution or inaccessibility of the objects of interest (subsea resources, reservoirs, wells) hence difficulty of relying on temporally and spatially bounded work practices. The unfolding of situated action in such settings extends across technological arrangements comprising heterogeneous interconnected remote instrumentation such as sensors, tools, gadgets, and measurement devices (i.e. IoT) generating potentially vast amounts of diverse or "big" data. What the nature of these data heaps entails for work, social, or private life is at the centre of a growing body of research [3], but the literature has mostly focused on the implications of Big Data for business [16].

However, this emerging stream of research has also highlighted the potential of IoT and Big Data in transforming services and reshaping the means and operations through 
which information becomes available for decision makers in organizations [16], as they have the potential to change the very nature of inquiry. Instead of affording the testing of human-generated hypothesis, smart algorithms are capable of actively asking new questions [3], thus rendering phenomena visible and knowable in novel ways that are never neutral, but constantly change the relationship among work, knowledge, and authority [17]. The majority of Big Data/IoT research, however, still tends to assume the data to be dematerialized [4], and the rhetoric associated with it conveys a technologically deterministic ideal devoid of the social [18].

Studying the sociomaterial nature of the data in "Big Data" is fundamental to understand how new IoT-inspired technological arrangements are performative in the sense that they do not only address, but also produce new phenomena [19]. "Big [D]ata owes much of its distinctiveness to the mechanisms by which it is generated and the messy or trivial everydayness these mechanisms help install at the heart of the processes of data generation and use" [16] (p. 46). In other words, datasets, the technological arrangements that generate them, and the practices in which they are immersed are coconstituted. We should therefore develop sensitivity to the way different entailments of these algorithmic phenomena play out and under what conditions [15].

This constitutive entanglement [11] has been investigated in synthetic situations where work relies almost entirely on making sense of digital datasets, due to the inherent distribution or inaccessibility of the phenomenon being studied. Østerlie and colleagues [20] for instance showcase how the material phenomena happening in the well flow during oil production (e.g. faulty sensors, sand, oil flow, high pressure) and the phenomenon that is observed (e.g. sand detection) remain undifferentiated until they are materialized in the real-time data as part of everyday epistemic practices to detect sand across the material arrangements of sensors, computing equipment, and algorithms. What these studies point to is that, due to the distance from the physical referents, algorithmic phenomena are the phenomena-sometimes triggering a "lure of the virtual" where practices based on virtual models tend to overlap with practices on virtual models [21].

An interesting avenue of research thus consists of demonstrating how algorithmic phenomena play out in synthetic situations. We analyse the synthetic practices of three communities of professionals in the oil and gas offshore sector. We focus on how the re-presentations of the phenomena that they monitor are performed in non-neutral ways through the practices and routines to make sense of the materiality of their imperfect monitoring instruments and algorithms, the digital data they generate, and physical reality.

\section{$3 \quad$ Research Setting and Methods}

Our analysis draws upon our joint and individual empirical studies of petroleum professionals' work practices in monitoring operations in all productive phases of offshore oil and gas operations. Offshore operations are an extreme case of synthetic situations as petroleum professionals are increasingly separated from the physical referents of 
their work practices through on-going efforts to introduce real-time data transfer solutions, increased bandwidth, better instrumentation, software that facilitates remote collaboration combined with relocating key personnel from offshore to onshore facilities. The synthetic realities brought about through these arrangements introduce high degrees of uncertainty, but petroleum professionals have learnt to deal with imperfect representations of the sea and the subsurface. Our shared focus has therefore been to study the unfolding of the sociomaterial arrangements that the petroleum professionals' work practices are part of.

Two longitudinal ethnographic studies provide our main empirical basis. Parmiggiani has conducted a three-year ethnography of developing approaches for realtime monitoring of marine ecosystems, and Østerlie has conducted a five-year ethnography on digitalization of the offshore petroleum industry. This is supplemented with Monteiro's sustained engagement with standardization of information systems and work practice in the petroleum industry over the past twenty years. Our research was conducted in close collaboration with petroleum companies, offering co-location with different groups of petroleum professionals as well as access to internal meetings together with workshops and seminars with technology vendors and partner companies. A central aspect of our inquiries has been to situate petroleum professionals' work in the broader landscape of technology development, adoption, and use. We therefore also asked people to trace the trajectories of past and ongoing development efforts, and their experiences and reflections about these processes. Table 1 summarizes our main sources of data.

Table 1. Summary of data generation methods

\begin{tabular}{|c|c|}
\hline $\begin{array}{l}\text { Participatory observa- } \\
\text { tions }\end{array}$ & $\begin{array}{l}\text { - } 3 \text { years with R\&D division (environmental monitor- } \\
\text { ing) } \\
\text { - } 4 \text { years with R\&D division (reservoir monitoring) } \\
\text { - } 2.5 \text { years with R\&D division (participating in a large- } \\
\text { scale digitalization project) } \\
\text { - } 11 \text { months in an onshore operation centre } \\
\text { - Daily and weekly meetings } \\
\text { - Conferences and seminars related to digitalization in } \\
\text { the oil and gas industry }\end{array}$ \\
\hline $\begin{array}{l}\text { Semi-structured inter- } \\
\text { views }\end{array}$ & $\begin{array}{l}\text { - } 38 \text { interviews with engineers and environmental ad- } \\
\text { visor involved in environmental monitoring pro- } \\
\text { grams } \\
\text { - } 24 \text { interviews with developers of new digital technol- } \\
\text { ogies for operational departments }\end{array}$ \\
\hline $\begin{array}{l}\text { Document and software } \\
\text { analysis }\end{array}$ & $\begin{array}{l}\text { - Electronic archives (internal documents and presen- } \\
\text { tations) } \\
\text { - Email discussions and minutes of meetings }\end{array}$ \\
\hline
\end{tabular}


- Intranet and internal team sites

- Internet-based public information

- Monitoring software in use or under development

The argument pursued in this paper emerged from our collective deliberations on the empirical material and the way it relates to current debates on digitalization and virtualization. Knorr Cetina's notion of synthetic situations was useful for understanding petroleum professional's work. Like Williams and Pollock [10], however, we also found notions of situatedness problematic as they would limit the study in terms of spatial and temporal framing and of relevant actors. We therefore sought to elaborate upon situatedness by bringing in aspects of the distributed and longitudinal nature of synthetic situations. To this end, we selected three empirical vignettes that intensely manifest the aspects with which we wish to enrich the notion of synthetic situations.

\section{$4 \quad$ Results}

\subsection{Monitoring the Drilling Activity}

NorthOil (a pseudonym) is a Scandinavia-based oil operator, whose Online Centre for Drilling (OCD) monitors in real time all well drilling activities conducted by the service companies hired by NorthOil. The OCD is a large open space situated in NorthOil headquarters. All real-time drilling datasets delivered by the drilling companies are screened in a standardized format on two large monitors next to the main entrance to the OCD and on all engineers' desktop computers. The main goal of the OCD is to monitor the technical quality of the incoming data from all the wells drilled on behalf of NorthOil, to ensure that they respond to the parameters in the contract between NorthOil and the driller, thus guarantee a return of investment for the company. The interface of the system for an external observer largely resembles generic spreadsheet software, where the data records are marked in either green if they lie within acceptable threshold values or red if they do not.

In general, the monitoring practices of the OCD are steered through computer-based in-office projections of worldwide distributed offshore drilling activities. The underlying idea is that specialized engineers should not be out on the rig in order to get access to real-time drilling data. Apparently, then, the scope of the work practices of the OCD spans the screens projecting the drilling data as soon as they become available. Each entry on the screen, however, has to be validated by considering the on-site assessments executed by the professionals on the offshore rig, on the one hand, and the formalized contract signed with the service company, on the other. Especially when a data record is marked red or an alarm goes off, the first thing to do is to understand the source of the problem and solve it as quickly as possible to prevent accidents. Typical errors are missing data, due to, e.g. a failure of one of OCD's streaming tools, the network, the sensors, or the systems used by the service companies on the rig. Some of these errors are, however, invisible to the OCD personnel: 
It could typically be that data is shifted for some reason. [If] the whole dataset ... is five meters too deep, or five meters too shallow, [the OCD] wouldn't be able to notice that. Or maybe all of the values are wrong and the service companies are multiplying it by a constant and that's slightly off what it's supposed to be, and that could be due to a calibration error in the sensors. (IT advisor, NorthOil)

Despite the seemingly isolated and aseptic environment in which they operate, the OCD engineers make sense of all data feeds by being constantly in telephone contact with the drilling companies:

We take the role of error searching and we are typically in dialogue with the service companies $24 / 7$, making sure that the error is fixed. So in many cases we discover the error before the users discover it. But in some occasions we have also [called the offshore personnel], saying "We are in a critical phase, we are missing data, can you please help us error search?” (IT advisor, NorthOil)

As a result, the OCD routines are fundamentally rooted in this dialogue with the remote drillers, because they are often physically co-located with the particular problem that is occurring and have thus a privileged knowledge of the characteristics of a well:

It's up to the data owners out in the asset, because they know the formation, they know they are supposed to hit this [subsurface rock] layer and so forth, they are fully responsible for the ... petro-physical quality of the data. And that requires a human to look at the screens and basically perform that type of checking. (IT advisor, NorthOil)

The situation of well drilling is also shaped by the specific contract that the drilling service company has signed with NorthOil. NorthOil has developed a penalty/bonus mechanism to either penalize or award service companies based on their capacity to provide trustworthy datasets. Penalties or bonuses are directly proportional to NorthOil's key performance indicators (KPIs), thus in turn to the money that a service company earns for drilling each well section.

[Our system] tells us which component is failing ... And we also register downtime ... there is actually a direct link between the performance, the KPIs, of the service companies, and the invoices ... It gives them a strong incentive to improve their deliverables, and to develop monitoring tools themselves. (IT advisor, NorthOil)

Translating technical data quality into money invites the service companies to monitor their data feeds as efficiently as possible to prevent a loss of money. Some service companies have for instance developed history-matching techniques to understand if the data feed from the drilling activity in one point are correct with reference to the previous feed collected while drilling holes in the same formation:

And then [some drilling companies] register all [the patterns of the drilling operations conducted in the area by others], and when they start to drill they [visualize] when the current values are very close to historical pattern, and then the alarm goes off you have to inspect. (IT advisor, NorthOil) 


\subsection{Monitoring for New Oil}

Exploring for new oil discoveries, the geology and geophysics (G\&G) specialist is at work in front of his computer constructing a digital model of subsurface formations from digital data at Alpha Petroleum Company (APC, a pseudonym). For many, this is a typical example of situated action in the age of computing. The G\&G specialist is physically co-located with his computer using an assortment of more or less specialized software for manipulating the data with keyboard and mouse in the here and now. The data this particular G\&G specialist is working on, however, stretches far back. These are old data that have already been processed in the past to build models of subsurface geological formations without finding any oil-bearing layers. The G\&G specialist is reopening the black box, seeking to discover what was not previously found in the data: geological layers containing oil. The G\&G specialist looks for new oil in old data where oil has previously not been present.

Seismic is a key data type in oil and gas exploration. It is generated in complex technical arrangements interacting with the ocean and subsurface formations. A series of long strings (several hundreds of meters) with hydrophones placed at regular intervals are tugged behind a boat moving in a regularized pattern across the area being charted. At set intervals a device drives sound waves into the ocean floor. Subsurface formations reflect these sound waves in different ways, and it is the reflected waves the hydrophones pick up. Before they can be used to model the underground in search of oil-bearing layers, these sound reflection data come to be entangled with a whole array of different algorithms and work practices filtering out noise and normalizing the data.

Seismics are quite messy. In general, digital sensor data often resonate with many other phenomena than those about which the sensors are designed to generate data. The construction of digital sensors is such that they may register noise, and occurrences in the particular situation when the data are generated will therefore register in the data. With seismic data, this noise needs to be identified and then removed before the data can be used to construct a model of subsurface formations. One of the first things to be done with the data is to correct for drift in the hydrophone setup. Currents and wind can make the lines drift to the left or right, distorting the sound reception. The spacing between the lines, which is important to analysis, can also shift. All this has to be corrected. The company producing the seismic data usually does this correcting, as it requires understanding of how line drift and spacing manifest in the data. Once corrected, it is time to remove noise. There are whole sound spectra that are considered noise, and will be removed by default. Only at this stage are the data ready to be used for constructing models. Things are, of course, never this simple, and prospecting for new oil in seismic data is a constant iteration between cleaning up the data and regressing to messier data to make sense of what is at hand. So when the G\&G specialist finally sits down with his or her computer to develop models, any oil-bearing geological structures that appear are very much the product of the long-winded, distributed process of generating and cleaning data.

However, it is this very noise that explorationists are now turning to in their constant quest for undiscovered occurrences of oil. Seeking new oil used to be a matter of finding unexplored areas. But as most territorial areas on the Earth have been explored, oil and 
gas companies are starting to investigate already explored areas for occurrences of oil that escaped their initial exploration. This, however, requires a lot more than just drilling more exploration wells. Instead, oil and gas companies turn their attention away from the physical world and to the world of digital data, which is the impetuous behind the activities of the G\&G specialists above.

"We have a theory", the manager in charge of APC's seismic technology development programme tells us, "a theory that we can use on a range of what has previously been regarded as noise to detect new kinds of oil-bearing formations". He is quite animated, the interview starting in mid-sentence as if picking up on a longstanding conversation. Speaking faster than we are able to follow, he comes across as a mad scientist type - like many of the other explorationists.

APC has set up a whole research programme to find ways to repurpose data noise in an effort to discover oil-bearing layers in areas that have already been explored. APC has recently discovered oil in an area that has previously been explored by other oil companies and found to be barren. The oil was found in structures deeper than previously expected to be oil-bearing. Now they have initiated a project to investigate if this particular oil-bearing structure can be found by including parts of what has previously been regarded as noise in the seismic data. To this end, they have handed the seismic raw data from this field to a company specializing in seismic interpretation to see if they are able to develop an algorithm to bring out this formation in the noise.

The particular analysis software our G\&G specialist is working with has been developed as part of this programme. His ability to find oil-bearing layers in the seismic data is contingent upon a broader background of development work.

\subsection{Monitoring the Marine Ecosystem}

The move of offshore operations into more remote settings such as offshore South America or the Arctic region is accompanied by an increased attention on efficiently monitoring the health of the marine environment. Subsea environmental monitoring was born as a set of disconnected and long-term tasks to collect samples of the water and the marine biomass conducted by third party consultants. Currently, it is evolving towards real-time approaches integrated with other operational phases such as well drilling and petroleum production, based on networks of heterogeneous subsea sensors, cameras, and other devices. The infinite qualities of the marine environment are thus quantified into potentially large amounts of datasets that are sent onshore via fibre-optic or satellite technologies. Given the relative novelty of these approaches, uncertainty still dominates with respect to how these data can be combined and interpreted.

Since the mid-2000s, NorthOil has initiated a promising real-time environmental monitoring system offshore north Scandinavia. The system consisted of a network of subsea sensors to measure water temperature, pressure, salinity, and other oceanographic parameters and a few acoustic devices to track fish and other moving resources. Given the density of cold-water coral structures in the Barents Sea, the main body of the sensor network was then connected to a 2-metre crane equipped with a subsea camera and a flash to take pictures of a nearby coral structure. As a result of the success of this solution with the company's management, in 2009 NorthOil decided to adopt the 
same concept to a newly acquired functioning oil production field off the coast of Brazil. The seafloor in the vicinity of the Brazilian field is densely populated by calcareous algae, and the Brazilian authorities' concern was that possible leakages caused by oil production might prevent the light from reaching these plants to enhance their photosynthetic process.

A set of sensors similar to those installed in the Barents Sea was set out to monitor the underwater environment around the operational field with the purpose of looking at possible oil leakages. The environmental experts at NorthOil soon discovered that the materiality of calcareous algae and that of the corals makes these creatures very different: completely different technological and analytical configurations were needed to perform them into an oil and gas operational context. First, whereas algae are plants, corals are animals and do not need as much light to grow, so the sensors developed to monitor their health did not take the light into account as a primary factor. In addition, the Arctic sensor network had been designed to monitor corals which can build structures of up to 20 metres. In contrast, calcareous algae are the size of a golf ball. In the Brazilian field there was therefore no need to install a satellite crane to position the camera, which could thus take pictures of the algae directly from the sea floor. The unsuitability of the sensors was accompanied by a series of unexpected electronic failures:

[W]e got a little damage on it so it registered data only for a short period, and then the batteries ran out, really a short circuit ... One part of the reason was that we went out of energy, another was that the sensors did not work as they should have then, so there was a deal of problems with corrosion and short circuits because the environment in [Brazil] is extremely corrosive. We had not taken that into account. (Environmental advisor, NorthOil)

The situation in Brazil was thus heavily shaped by its natural characteristics; the Brazilian waters are very different from the Norwegian waters, they are warmer, more saline, and currents are stronger, meaning that the Brazilian marine ecosystem is more corrosive than NorthOil environmental experts initially expected. Failing to take this aspect into account caused a number of technical failures that did not allow the program to gather sufficiently good data streams. As a countermeasure, the support structure was rebuilt in titanium and designed such that all sensors were much more protected from the water current.

Eventually, the data collection was carried out successfully. The internal analysis of what went wrong during the first monitoring rounds turned the company's attention to a phenomenon they were not looking for originally, namely damages caused by the corrosive effects of the water on the nearby oil platform that would have otherwise remained unnoticed and caused serious accidents:

It came as a big surprise for the whole organisation, so we have conducted massive reinforcements or measures in relation to the platform which stands there. It's a little stupid if the platform suddenly disappears! (Environmental advisor, NorthOil)

Environmental monitoring strongly relates to safety in the Brazilian case. Given that the planning of the platform had been done by another company, it also emphasized the 
importance of carefully weaving environmental monitoring practices to the company's business choices:

[It is a] typical example that [...] shows a very special example of the extreme need to have good meteorological and oceanographic data before you go in. One thing is in a way the environmental measurements, but in relation to the safety part, it is totally essential. (Environmental advisor, NorthOil)

\section{Discussion}

Our three empirical vignettes resonate with the concept of synthetic situation, defined as informational projected "others" with which humans interact and which evolve over time [7]. Oil and gas professionals necessarily rely on evolving digitalized forms of knowing such as simulations and real-time computerized analysis to interpret events they cannot access directly. In the case of reservoir monitoring, knowledge about the presence of oil develops along a temporal dimension as data analysis is a process distributed in time and space through the seismic data and the software used. The G\&G specialists' activities for using seismic data to assemble a model of the underground are therefore shaped by contingencies that evolve over time and stretch beyond the specifics of particular computer or software in use.

Moreover, the phenomena under investigation (the presence of oil, the drilling activity, environmental risk) are algorithmic, namely enacted through digital technologies. However, the performative nature of synthetic situations - i.e. the extent to which they constitute the object of enquiry by enacting relationships in practice [6] - in technology-saturated settings such as oil and gas offshore operations remains underdeveloped. We elaborate upon the performativity of synthetic situations in three ways.

First, in our empirical cases algorithmic phenomena are the phenomena, rather than standing in for the physical referents. The discovery of new trends and latent patterns (viz. new phenomena) without well-formed hypotheses or models is a promise of Big Data analytics [4], but the way the data are caught up in the material means of their production is understudied in that literature [4]. The G\&G personnel, by re-interpreting the old datasets, are able to discover new trends and patterns to understand if oil is present. Similarly, the environmental advisors conducting environmental monitoring in Brazil are able to make sense of a phenomenon they were not originally looking for, i.e. potential environmental harm caused by the corrosive effect of the water on the oil platform. These situations are, thus, beyond synthetic, in the sense that they are algorithmic, i.e. entirely dependent on the tuning of sociomaterial arrangements of the monitoring systems [15]: the presence of an oil-bearing layer in the seismic data and the corrosive effect of the Brazilian waters are never independent of the digital data processing algorithms.

Second, noise is irreducible in algorithmic phenomena. Big Data techniques as synthetic situations are often intended as ways to cope with exceeding amounts of information by being able to filter out the noise. In our study, however, it is never possible to filter out the noise, because, as the world is constantly enacted and re-enacted through material-discursive practices [15], the noise becomes the source of new knowledge. In 
this process, oil and gas professionals engage with the "dual materiality" of phenomena [20]: they go constantly beyond the screen to worry about data quality, sensor reliability, i.e. the material circumstances of the data that make up their synthetic situation. This also differs from Knorr Cetina's example of a scoping system [7], where traders are able to successfully filter out the noise without systematically going beyond the screen. In contrast, the monitoring activities in oil and gas offshore operations involve the material circumstances of data processing (algorithms, simulations, and analysis tools), as well as the material circumstances of data production.

This foregrounds a third way in which our study extends Knorr Cetina's concept: the synthetic situation is productive rather than reductive. What originally looks like noise that must be reduced is in fact a new situation. Zuboff [18] for example shows how Google managed to create enormous revenues by turning apparent noise generated by Internet users into a marketable asset for commercial and surveillance purposes. Similarly, the process of re-processing the old datasets from oil exploration showcases that the situation for the G\&G personnel is actually constituted by what was originally considered noise. This, too, proves to have business value for APC. At the OCD, drilling monitoring unfolds in a synthetic situation that looks like that of the traders described by Knorr Cetina [7]: the OCD personnel must rely on on-screen projections to make sense of a remote reality. Nevertheless, the apparent noise - namely the overhead of work to call and talk to the offshore engineers - turns out to be a pivotal part of their synthetic situation, which therefore extends behind the screen to encompass the informal machinery of sense-making enacted by the offshore personnel in communication with the OCD. The synthetic situation of the OCD is also further extended on the formal level, by tying the sense-making practices (which the OCD personnel know unfold informally) to contractual clauses and KPIs. Finally, also environmental harm offshore Brazil emerged out of the noise, namely the bad quality data obtained as a result of short circuits and damages to the monitoring station, and the associated workarounds to repair it. In this case, the situation encompasses also the (apparently mundane) interactions of social and technical elements with the materiality of nature to make sense of natural phenomena with good enough approximation.

\section{Conclusions}

Our paper takes steps towards conducting interpretive studies of knowing in the era of Big Data and the IoT - namely through synthetic situations characterized by physical inaccessibility (such as the energy industry and space exploration) and virtualization (such as the car industry [21]). Our analysis has also methodological implications, as the variety and uncertainty of the data involved challenge the dynamics of traditional qualitative research bounded in space and time. Focusing on the productivity of algorithmic phenomena implies a shift of focus from the actors' meanings to include what sociomaterial assemblages "do" in practice [6]. We accordingly supplemented our interpretivist method by scaling access and capture the longitudinal and distributed nature of both the development and use of digital enterprise technology [10]. We in other 
words investigated the way datasets "travel", namely how an interpretation is performed together with the materiality of both the physical reality and the algorithms behind the evidence that makes it the right interpretation. This perspective on the quantification of quality recognizes that algorithms are performative of categories (e.g. what is noise) and ultimately have political implications in terms of legitimizing human actions [22] and shifting knowledge/power relations [17].

\section{Acknowledgements}

This research was supported by the following projects funded by the Norwegian Research Council: Digital Oil (www.doil.no; \#213115); Sirius (www.sirius-labs.no; \#237889); and the Center for Integrated Operations in the Petroleum Industry (www.iocenter.no).

\section{References}

1. Suchman, L.A.: Plans and Situated Actions: The Problem of Human-Machine Communication. Cambridge University Press, Cambridge (1987)

2. Orlikowski, W.J.: Using Technology and Constituting Structures: A Practice Lens for Studying Technology in Organizations. Organization Science. 11, 404-428 (2000)

3. Agarwal, R., Dhar, V.: Editorial - Big Data, Data Science, and Analytics: The Opportunity and Challenge for IS Research. Information Systems Research. 25, 443-448 (2014)

4. Lycett, M.: "Datafication": Making Sense of (Big) Data in a Complex World. European Journal of Information Systems. 22, 381-386 (2013)

5. Monteiro, E., Almklov, P.G., Hepsø, V.: Living in a Sociomaterial World. In: Bhattacherjee, A. and Fitzgerald, B. (eds) Shaping the Future of ICT Research: Methods and Approaches. pp. 91-107. Springer, Berlin Heidelberg (2012)

6. Barad, K.: Posthumanist Performativity: Towards an Understanding of How Matter Comes to Matter. Journal of Women in Culture and Society. 28, 801-831 (2003)

7. Knorr Cetina, K.: The Synthetic Situation: Interactionism for a Global World. Symbolic Interaction. 32, 61-87 (2009)

8. Pollock, N., Williams, R., D'Adderio, L., Grimm, C.: Post Local Forms of Repair: The (Extended) Situation of Virtualised Technical Support. Information and Organization. 19, 253276 (2009)

9. Kallinikos, J.: Farewell to Constructivism: Technology and Context-Embedded Action. In: Avgerou, C., Ciborra, C., and Frank, L. (eds) The Social Study of Information and Communication Technology: Innovation, Actors and Contexts. pp. 140-161. Oxford University Press, Oxford (2004)

10. Williams, R., Pollock, N.: Research Commentary - Moving Beyond the Single Site Implementation Study: How (and Why) We Should Study the Biography of Packaged Enterprise Solutions. Information Systems Research. 23, 1-22 (2012)

11. Orlikowski, W.J., Scott, S.V.: Sociomateriality: Challenging the Separation of Technology, Work and Organization. The Academy of Management Annals. 2, 433-474 (2008)

12. Cecez-Kecmanovic, D., Galliers, R., Henfridsson, O., Newell, S., Vidgen, R.: The Sociomateriality of Information Systems: Current Status, Future Directions. Management Information Systems Quarterly. 38, 809-830 (2014) 
13. Suchman, L.: Human-Machine Reconfigurations: Plans and Situated Actions. Cambridge University Press, Cambridge (2006)

14. Monteiro, E., Rolland, K.H.: Trans-situated Use of Integrated Information Systems. European Journal in Information Systems. 21, 608-620 (2012)

15. Orlikowski, W.J., Scott, S.V.: Exploring Material-Discursive Practices. Journal of Management Studies. 52, 697-705 (2015)

16. Constantiou, I.D., Kallinikos, J.: New Games, New Rules: Big Data and the Changing Context of Strategy. Journal of Information Technology. 30, 44-57 (2015)

17. Zuboff, S.: In the Age of the Smart Machine: The Future of Work and Power. Basic Books, New York (1988)

18. Zuboff, S.: Big Other: Surveillance Capitalism and the Prospects of an Information Civilization. Journal of Information Technology. 30, 75-89 (2015)

19. Boos, D., Guenter, H., Grote, G., Kinder, K.: Controllable Accountabilities: The Internet of Things and its Challenges for Organisations. Behaviour \& Information Technology. 32, 449-467 (2013)

20. Østerlie, T., Almklov, P.G., Hepsø, V.: Dual Materiality and Knowing in Petroleum Production. Information and Organization. 22, 85-105 (2012)

21. Bailey, D.E., Leonardi, P.M., Barley, S.R.: The Lure of the Virtual. Organization Science. 23, 1485-1504 (2011)

22. Kavanagh, D., McGarraghy, S., Kelly, S.: Ethnography In and Around an Algorithm. Presented at the 30th EGOS Colloquium: Sub-theme 15: (SWG) Creativity, Reflexivity and Responsibility in Organizational Ethnography, Athens, Greece July 3 (2015) 